\title{
Tratamento Jurídico da Proteção e Defesa do Usuário de Serviços Públicos
}

\author{
Roberta Bagatini Bassegio
}

\section{INTRODUÇÃO}

A discussão acerca do papel desempenhado pelo Estado nas relações econômicas, dos modelos que defendem sua maior ou menor intervenção e de sua atuação direta ou indireta na condução dos negócios de um país certamente não é matéria nova, mas realidade sujeita a inúmeras alterações ao longo da história, sempre em busca da realização de uma finalidade essencial: a satisfação da coletividade que forma o Estado em questão.

Deste debate emergem, fundamentalmente, duas esferas distintas de atuação, Quais sejam, a atividade econômica e os serviços públicos, dentro das Quais o Estado se apresenta de variadas formas. As relações que se estabelecem entre o Estado e os demais agentes privados Que atuam nestes cenários submetem-se a diferentes regimes jurídicos - ora concorrencial, ora de delegação, ora de fiscalização, entre outros -, cada Qual com contornos específicos.

O objetivo central do presente estudo tratará da Questão sobre a perspectiva do indivíduo que busca usufruir dos serviços públicos, Quer prestados diretamente pelo Estado. Quer indiretamente, mediante delegação a concessionários e permissionários.

Sob este enfoque, é certo que o Estado deve se fazer presente para regular tais relações, protegendo os interesses dos indivíduos e da coletividade e coibindo abusos por parte dos prestadores de serviço.

O que aqui se pretende investigar, contudo, é a forma com que essa proteção se dará no âmbito do serviço público, em especial no Que diz respeito à existência de eventual identidade ou equivalência entre o regime jurídico dos serviços públicos e aquele Que regulamenta as atividades econômicas frente ao consumidor.

Em síntese, abordar-se-á, neste trabalho, as diferenças existentes entre a figura do "consumidor", entendido como aquele que usufrui das atividades econômicas privadas, e do "usuário", entendido como aquele que usufrui de um serviço público, a fim de analisar o regime jurídico aplicável à proteção dos direitos deste último. 
Serão apresentadas, inicialmente, as normas infraconstitucionais privadas de proteção e defesa do consumidor e o entendimento da doutrina acerca de sua aplicação aos usuários de serviço público, em face, também, das normas infraconstitucionais de direito administrativo.

A aplicabilidade do direito do consumidor ao usuário de serviços públicos será, a seguir, analisada a partir da perspectiva do direito constitucional, destacando-se os regimes jurídicos eleitos pela Constituição Federal para disciplinar as atividades econômicas e os serviços públicos.

Ao final, investigar-se-á a possibilidade, diante da aparente distinção entre os dois regimes, de compatibilizar as normas consumeristas privadas com aquelas atinentes à proteção do usuário de serviço público, bem assim de que forma poderá tal compatibilização ser admitida e implementada.

\section{TRATAMENTO DO USUÁRIO DE SERVIÇO PÚBLICO PELA LEGISLAÇÃO INFRACONSTITUCIONAL}

\subsection{Do contexto em oue se insere a ouestão da defesa dos direitos do usuário de SERviço público}

Mesmo em face das constantes evoluções experimentadas na forma de atuação do Estado no campo econômico e da gradual ampliação do campo das atividades econômicas submetidas à livre iniciativa, é inegável a importância que os serviços públicos ainda representam na sociedade contemporânea.

Especialmente após o período de privatizações e da delegação de parte considerável da prestação de serviços públicos à iniciativa privada, por meio de concessões e permissões, a disciplina das relações estabelecidas entre prestadores e usuários no âmbito desses serviços vem ganhando crescente importância.

Da mesma forma com Que se percebeu, no âmbito das relações entre privados, Que o direito civil não se mostrava eficaz para disciplinar a relação estabelecida entre o consumidor e o fornecedor de produtos e serviços, em face da mitigaçăo dos pressupostos da liberdade de contratação e da igualdade de condições negociais entre as partes, tornou-se claro, também no âmbito dos serviços públicos, Que as normas desenhadas para regular os contratos administrativos entre a Administração Pública e seus fornecedores não é suficiente para proteger os interesses dos usuários dos serviços públicos.

No primeiro caso, o reconhecimento da vulnerabilidade e da hipossuficiência do consumidor frente ao poder econômico do mercado fornecedor na relação de consumo demandou a necessidade da edição de regras próprias a fim de restabelecer um estado de equilbbrio entre as partes, dando origem ao tão aclamado Código de Proteção e Defesa do Consumidor. 
No segundo, atinente à proteção dos usuários dos serviços públicos, a inexistência de legislação específica levanta Questionamentos ainda não suficientemente explorados, no Que diz respeito, principalmente, à compatibilização entre a proteção do direito do usuário individualmente considerado e as características inerentes aos contratos administrativos, destinadas à proteção do interesse público como um todo.

Importa analisar, neste contexto, de Que forma a defesa dos direitos do usuário de serviços públicos poderá ser implementada, em especial diante do Que dispóe a legislação atualmente em vigor.

\subsection{0 usuário de serviço público e o Códiqo de Proteção e Defesa do Consumidor}

A garantia da proteção aos consumidores e a necessidade de criação de regras próprias capazes de tornar tal proteção efetiva foram acolhidas pela Constituição Federal de 1988, que em seu art. 5०, XXXII impôs ao Estado a promoçāo, na forma da lei, da defesa do consumidor ${ }^{1}$. Para assegurar a colocação em prática de tal garantia, 0 art. 48 do Ato das Disposições Transitórias fixou um prazo máximo de 120 dias para a elaboração de um código de defesa do consumidor ${ }^{2}$.

Com algum atraso, em 1990 foi promulgada a Lei no 8.078 , o chamado "Código de Proteção e Defesa do Consumidor", Que tem por objetivo, conforme previsto em seu art. $1^{\circ}$, o estabelecimento de normas de proteção e defesa do consumidor, de ordem pública e interesse social ${ }^{3}$.

Tendo em vista sua importância e efetividade na defesa dos interesses dos consumidores, cumpre investigar a possibilidade de abarcar, na disciplina do referido Código, também a defesa dos usuários de serviços públicos.

1 Para o Que ora importa, assim dispöe tal artigo: Art. $5^{\circ}$ Todos săo iguais perante a leị, sem distinção de Qualouer natureza, garantindo-se aos brasiteiros e aos estrangeiros residentes no País a inviolabilidade do direito à vida, à liberdade, à igualdade, à segurança e à propriedade, nos termos seguintes:

(...) XXXII - o Estado promoverá, na forma da lei, a defesa do consumidor;

2 Da seguinte forma:

Art. 48. O Congresso Nacional, dentro de cento e vinte dias da promulgą̧ão da Constitulçäo, elaborará código de defesa do consumidor.

3 Dispōe o referido artigo:

Art. $1^{\circ}$ O presente código estabelece normas de protę̧ão e defesa do consumidor, de ordem pública $e$ interesse social, nos termos dos arts. $5^{\circ}$, inciso XXXII, I70, inciso V, da Constituiçăo Federal e art. 48 de suas Disposiçöes Transitórias. 
O Código de Proteção e Defesa do Consumidor ocupou-se de definir, inicialmente, as duas partes elementares da relação de consumo: o consumidor e o fornecedor ${ }^{4}$. Ao fazêlo, utilizou-se conceitos exclusivamente econômicos e não jurídicos ${ }^{5}$, razão pela qual ambos os conceitos, previstos nos art. $2^{\circ}$ e $3^{\circ}$ do Código, são bastante amplos, visando a abranger Quaisquer relações de aquisição ou utilização de produtos ou serviços.

Em Que pese sua amplitude, tais conceitos não se mostram suficientes para, isoladamente, determinar a aplicação ou não do referido Código ao âmbito dos serviços públicos, a fim de alcançar também a tão necessária defesa dos interesses dos usuários destes serviços.

De fato, a afirmação de que o consumidor é também aquele que contrata um serviço não pressupõe, de per se, Que a contratação de um serviço público caracterizaria " relação de consumo" para fins de aplicação das regras do Código de Proteção e Delesa do Consumidor. Tampouco a conceituação de fornecedor como a pessoa física ou jurídica que desenvolve atividade de prestação de serviços não esclarece a Questão, porquanto não delimita o conceito de serviço.

Nem mesmo o conceito de serviço estabelecido no Código é suficientemente preciso para determinar a inclusão ou não, em seu bojo, do serviço público, uma vez que se limita o $\S 2^{\circ}$ do art. $3^{\circ}$ a afirmar: "Serviço é Qualquer atividade fornecida no mercado de consumo, mediante remuneração, inclusive as de natureza bancária, financeira, de crédito e securitária, salvo as decorrentes das relações de caráter trabalhista".

Não há dúvidas, no entanto, de Que o Código de Proteção e Defesa do Consumidor pretende alcançar, em seu âmbito de aplicação, também a proteção ao usuário de serviços públicos.

4 Tais conceitos encontram-se nos artigos $2^{\circ}$ e $3^{\circ}$ da Lei $n^{\circ} 8.078 / 90$, in verbis:

Art. $2^{\circ}$ Consumidor é toda pessoa física ou jurídica que adquire ou utiliza produto ou serviço como destinatário final.

Parágrafo único. Equipara-se a consumidor a coletividade de pessoas, ainda Que indetermináveis, Que haja intervindo nas relaçôes de consumo.

Art. $3^{\circ}$ Fornecedor é toda pessoa física ou jurídica, pública ou privada, nacional ou estrangeira, bem como os entes despersonalizados, Que desenvolvem atividade de produção, montagem, criação, construçăo, transformação, importação, exporlação, distribuição ou comercialização de produtos ou prestação de serviços.

$\S 1^{\circ}$ Produto ć Qualquer bem, móvel ou imóvel, material ou inaterial.

$\S 2^{\circ}$ Serviço é Qualquer atividade fornecida no mercado de consumo, mediante remuneraçäo, inclusive as de natureza bancária, financeira, de crédito e securitária, salvo as decorrentes das relaçöes de caráter trabalhista.

s FILOMENO. losé Geraldo Brito in GRJNOVER, Ada Pellegrini. et al. Código brasileiro de defesa do consumidor: comentado pelos autores do anteprojeto. 5. ed. Rio de laneiro: Forense Universitária, 1998, p. 17 e 25. 
Essa afirmativa tem por base os enunciados encontrados no art. $4^{\circ}$, VIl e no art. $6^{\circ}$, $\mathrm{X}$ Que dispóem, genericamente, sobre a methoria dos serviços públicos como objetivo a ser perseguido pela Administração e sobre o direito à prestação adequada e eficaz dos serviços públicos ${ }^{6}$

Mas é principalmente quando combinados tais enunciados e conceitos com o Quanto previsto no art. 22, encontrado na Seção do Código que trata da Responsabilidade por Vício do Produto e do Serviço, que se percebe a clara intenção de abranger, na disciplina do Código, também as relações estabelecidas entre o usuário e o prestador de serviços públicos ${ }^{7}$.

Assim, se os conceitos básicos adotados pelo Código de Proteção e Defesa do Consumidor não permitem concluir pela extensão de sua aplicação à relação estabelecida entre usuário e prestador de serviço público, os artigos $4^{\circ}, 6^{\circ}$ e 22 acima mencionados deixam absolutamente clara a intenção de abranger a regulamentação desta relação na disciplina do Código.

É precipuamente por conta destes dispositivos que a aplicação do Código de Proteção e Defesa do Consumidor aos serviços públicos tem sido amplamente corroborada pela doutrina especializada na análise dos direitos do consumidor, bem como pela jurisprudência pátria.

No Que tange à doutrina, os principais pontos levantados referem-se à aplicabilidade do Código aos prestadores de serviço público, inciuindo a própria Administração Pública ${ }^{8}$ e as concessionárias de serviço público ${ }^{9}$, à responsabilidade do Estado Quando prestador de serviço público por conta do art. $22^{10} \mathrm{e}$ às conseQüências cabíveis em face da prestaçāo inadequada de tais serviços"

- Para o que ora importa, le-se no primeiro dispositivo: Art. $4^{\circ} \mathrm{A}$ Política Nacional das Relaçöes de Consumo tem por objetivo o atendimento das necessidades dos consumidores, o respeito à sua dignidade, saúde e segurança, a proteção de seus interessses econômicos, a mehoria da sua qualidade de vida, bem como a transparência e harmonia das relaçóes de consumo, atendidos os seguintes princípios:

(..)

VII - racionalização e melhoria dos serviços públicos: E, no segundo, lê-se o que segue: Art. $6^{0}$ São direitos básicos do consumidor:

(...)

$X$ - a adequada e eficaz prestação dos serviços públicos em geral.

7 Afirma o art. 22: Art. 22. Os órgãos públicos, por si ou suas empresas, concessionárias, permissionárias ou sob Qualquer outra forma de empreendimento, são obrigados a fornecer serviços adequados, eficientes, seguros e, Quanto àos essenciais, contínuos.

Parágrafoúnico. Nos casos de descumprimento, total ou parcial, das obrigaçōes referidas neste artigo, serão as pessoas jurídicas compelidas a cumpri-las e a reparar os danos causados, na forma prevista neste código.

8 Neste sentido, losé Geraldo Brito Filomeno in lbid., p. 36.

9 Sobre o assunto, veja-se também: SAAD, Gabriel Eduardo. Comentários ao Código de Defesa do Consumidor: lei n. 8.078. de 11.9.90. 4. ed. Săo Paulo: LTr, 1999, p. 84.

(a) Ibid., p. 289.

"Veja-se, sobre a aplicabilidade dos arls. 14 e 20, o Que leciona Zelmo Denari in GRJNOVER, Ada Pellegrini. et ał., op. cit. p. 179. 
Destaca-se como ponto convergente desta parcela da doutrina a ausência de Questionamentos acerca da aplicabilidade do Código de Proteção e Defesa do Consumidor às relações estabelecidas entre os usuários e os prestadores de serviço público senão com base nas normas do próprio Código, razão pela Qual a única exceção por ela admitida diz respeito ao serviço gratuito, Que o art. $3^{\circ}$ tratou expressamente de afastar de sua disciplina.

De fato, atendendo a exigência formulada pelo próprio Código ao conceituar serviço ${ }^{\mathrm{i}}$, Qual seja, de que ele seja fornecido mediante remuneração, é consenso na doutrina de que não estariam submetidos a tais regras ąueles serviços prestados gratuitamente ou cuja remuneração advém de recursos arrecadados por meio de impostos, classificados com serviços públicos uti universi ${ }^{13}$. Apenas os serviços públicos uti singolari, prestados mediante remuneração direta, Quer por meio de taxa ou de tarifa, é que estariam abrangidos pelas regras consumeristas ${ }^{14}$.

losé Geraìdo Brito Filomeno ${ }^{15}$ restringe ainda mais a aplicação do Código de Proteção e Defesa do Consumidor aos usuários de serviço público afirmando Que, Quando a remuneração se dá por meio de qualquer espécie tributária, incluindo as taxas, a relação será de natureza tributária, afastando a incidência do direito do consumidor. Para o autor, não há que se confundir o contribuinte com o consumidor, de modo Que apenas os serviços públicos remunerados pela tarifa, ou preço público, prestados diretamente pelo poder público ou mediante concessão ou permissăo pela iniciativa privada é Que estarão sujjeitos às normas do Código de Proteção e Defesa do Consumidor.

Na esteira da doutrina de direito privado, a aplicação do Código de Proteção e Defesa do Consumidor ao usuário de serviços públicos vem se difundindo na jurisprudência pátria, tendo os tribunais nacionais, freqüentemente, promovido a defesa destes usuários com base nos preceitos da Lei $n^{\circ} 8.078 / 90$ sem Questionamentos mais profundos acerca de sua constitucionalidade ${ }^{16}$.

${ }^{12}$ Conforme conceito previsto no art. $3^{\circ}, \S 2^{\circ}$, já citado.

13. Serviços públicos uti universi são aqueles prestados à coletividade, usufruídos apenas indiretamente pelos indivíduos. fá os serviços públicos uti singoliou uti singolarisăo aqueles Que visam a satisfazer as necessidades individuais e diretas dos cidadãos. Sobre os conceitos e diferenças entre as duas espécies de serviços públicos, veja-se: MEIRELLES, Hely Lopes. Direito Administrativo Brasileiro. 25. ed. São Paulo: Matheiros, 2000. p. 309; DI PIETRO, Maria Sylvia Zanella. Direito Administrativo. 13. ed. São Paulo: Atlas, 2001, p. 104 e OLIVEJRA, Ruth Helena Pimentel de. Entidades Prestadoras de Serviços Públicos e Responsabilidade Extracontratual. Săo Paulo: Atlas. 2003, p. 36.

14 Neste sentido, veja-se: MARQueS, Cláudia Lima. Contratos no Código de Defesa do Consumidor: o novo regime das relaçöes contratuais. 3. ed. São Paulo: Editora Revista dos Tribunais, 1998, p. 21 !; GROTTI, Dinorá Adelaide Musetti. O Serviço Público e a Consıituição Brasileira de 1988. São Paulo: Malheiros, 2003, p. 345; NASCiMENTO, Tupinambá Miguel Castro do. Comentários ao código do consumidor. Rio de Janeiro: Aide, 1991, p. 25-26.

15 GRINOVER, Ada Pellegrini. et al., op. cit., p. 41.

${ }^{16}$ Veja-se, neste sentido, a jurisprudência do Tribunal de lustiça do Rio Grande do Sul, Que têm sido unânime ao aplicar o Código de Defesa do Consumidor ao âmbito dos serviços públicos nas mais diversas situaçóes. conforme demonstram, exemplificativamente, os seguintes acórdăos: $\mathrm{AC} \mathrm{n}^{0} 70008133563$, julgado em 


\subsection{O usuário de serviço público e a Lei Geral das Concessóes de Serviço Público}

Não obstante se vislumbrem semelhanças no Que se refere à posição ocupada pelo usuário de serviço público em relação àQuela ocupada pelo consumidor, mormente no Que toca à sua vulnerabilidade, sustentar a aplicação do Código de Proteção e Defesa do Consumidor ao usuário de serviços públicos com base, unicamente, nas regras do próprio Código, é passível de questionamento.

Após a publicação da Lei no $8.987 / 95$, Que ao tratar das regras gerais aplicáveis às concessões e permissões de serviço público estabeleceu, em seu art. $7^{\circ}$, os direitos e deveres dos usuários de serviço público, afirmando que "sem prejuízo do disposto na Lei $n^{o}$ 8.078, de I/ de setembro de 1990, são direitos e obrigaçôes do usuário: (...)", as dúvidas até então existentes puderam ser parcialmente afastadas.

Tal artigo seria o reconhecimento, pelo direito administrativo, da aplicabilidade do direito do consumidor às relaçọes estabelecidas entre usuários de serviços públicos e seus prestadores, em especial com a admissão técnica e faticamente da vulnerabilidade dos usuários ${ }^{17}$.

Mesmo Quando já admitida ${ }^{18}$ a aplicabilidade plena do Código de Proteção e Defesa do Consumidor ao usuário de serviço público em razão dos dispositivos da própria lei consumerista, a ressalva efetuada no caput do art. $7^{\circ}$ da Lei $n^{\circ} 8.987 / 95$ mostrou-se importante para reforçá-la, demonstrando a intercambialidade entre o sistema do Código de Proteção e Defesa do Consumidor e a legislação específica Que rege a proteção dos usuários no regime da concessão.

Diante de tal conjugação de normas, surgiu o entendimento de Que caberia ao intérprete a aplicação daquela Que melhor favorecesse o usuário, de modo que nenhum dos direitos estabelecidos pelas regras específicas de direito administrativo poderia ser interpretado para restringir o alcance de Quaisquer dos direitos previstos no Código de Proteção e Defesa do Consumidor ${ }^{19}$. A leitura correta ${ }^{20}$ do art. $7^{\circ}$ da Lei $8.987 / 95$ seria, assim, a de Que os direitos subjetivos estabelecidos em tal lei são acrescentados a aQueles previstos no Código de Proteção e Defesa do Consumidor, emprestando a esta norma, em razão de seu sentido protetivo do consumidor, preferência de aplicação.

24/03/2004; AC n० 70005913108, julgado em 09/09/2004; AC no 70007725047, julgado em 06/ 10/2004; $A C n^{\circ} 70009844499$, julgado em 29/12/2004; AC no 70010310860, julgado em 22/12/ 2004; Al no 70010910032, julgado em 16/02/2005.

17 GROTTI, Dinorá Adelaide Museiti, op. cit., p. 342.

18 PFEIFFER, Roberto Augusto Castellanos. Serviços públicos concedidos e proteção do consumidor. Conferências do $5^{\circ}$ Congresso Brasileiro de Direito do Consumidor. Revista de Direito do Consumidor. São Paulo, Revista dos Tribunais, n. 36, p. 164-176, outubro-dezembro 2000, p. 165.

* Ibid., p. 165-166.

${ }^{20}$ MIRAGEM, Bruno. A regulação do serviço público de energia elétrica e o direito do consumidor. Revista de Dircito do Consumidor, São Paulo, Revista dos Tribunais, n. 51, p. 68-100, julho-sctembro 2004, p. 81 . 
Se alguma dúvida ainda houvesse ${ }^{21}$, o estabelecimento do vínculo direto entre a Lei Geral de Concessões e o Código de Proteção e Defesa do Consumidor teria, assim, afastado a idéía de que este último não pudesse alcançar as concessionárias de serviço público.

De fato, a partir da publicação Lei Geral de Concessões e na esteira do Que a doutrina especializada na análise dos direitos do consumidor já vinha pregando, passou-se a identificar também entre as obras de direito administrativo uma tendência à utilização do Código de Proteção e Defesa do Consumidor para a regulamentação da relação estabelecida entre usuário e prestador de serviço público ${ }^{22}$.

Em sentido semelhante ao invocado pela doutrina privatista, passou-se a admitir, na esfera do direito administrativo, a aplicação do Código de Proteção e Defesa do Consumidor no mínimo aos serviços públicos comerciais e industriais remunerados mediante tarifa ${ }^{23} \mathrm{e}$, em especial, para reforçar ${ }^{24}$ a responsabilidade objetiva do concessionário e permissionário de serviços públicos ditada pelo art. $37, \S 6^{\circ}$, da Constituição Federal, invocando o já mencionado art. 22 do Código de Proteçấo e Defesa do Consumidor.

Mesmo aqueles que reconhecem ${ }^{25}$ Que o art. 175 da Constituição Federal exige a edição de lei para dispor sobre o direito dos usuários de serviço público, chegam a admitir a aplicação do existente Código de Proteção e Defesa do Consumidor para regular a prestação de serviços públicos diretamente pela Administração Pública.

Também a jurisprudência, ao tratar conjuntamente das Leis $n^{\circ}$ 8.078/90 e 8.987/ 95 , utiliza-se do art. $7^{\circ}$ desta última para ressaltar a aplicabilidade da primeira aos usuários de serviço público, conforme se verifica em alguns julgados do Superior Tribunal de Justiça ${ }^{26}$.

\subsection{Visáo conjunta das normas de direito privado e das normas de direito administrativo}

Ainda assim, resta uma parcela da doutrina que entende que o Código de Proteção e Defesa do Consumidor deva ser aplicado com cautela aos usuários de serviço público, ressaltando para tanto peculiaridades intrínsecas ao regime jurídico no Qual estes últimos são prestados.

21 CAPELETTO, Gílberto José. Direito dos Consumidores e Regulação dos Serviços Públtcos. Marco Regulatório, Porto Alegre, AGERGS, n. 4, p. 31-63, 2001. p.50.

2. Sobre o assunto veja-se: BLANCHET, Luiz Alberto. Concessão de Serviços Públicos. 2. ed. Curitiba: Juruá, 1999. p. 61; MEIRELLES, Hely Lopes. Licitação e Contrato Administrativo. 12. ed. São Paulo: Malheiros, 1999, p. 286; MOOR, Fernanda Stracke. O Regime de Delegação da Prestação de Serviços Públicos. 1. ed. Porto Alegre: Livraria do Advogado, 2002, p. 17 e 39.

${ }^{23}$ OLIVEIRA, Ruth Helena Pimentel de. op. cit., p. 194 e 196.

${ }^{24}$ FIGUEIREDO, Lúcia Valle: Curso de Direito Adninistrativo. 6. ed. Säo Paulo: Mahheiros, 2003, p. 96.

${ }^{25}$ GASPARIN], Diógenes. Direito Administrativo. 4. ed. São Paulo: Saraiva, 1995, p. 217 e 220.

${ }^{25}$ Veja-se, entre outros, os Acórdãos do RESP n 393943/MG, de 01/03/2003; do RESP no 337965/MG, de 08/11/2004 e do RESP no 615705/PR, de 13/12/2004. 
A existência de diferenças essenciais entre as atividades privadas e o serviço público, Que se estendem desde a titularidade dos serviços e o interesse visado pelo prestador até as prerrogativas concretas conferidas ao poder concedente, foi ressaltada por Marçal Justen Filho $^{27}$ ao expressar sua perplexidade frente à cumulatividade da aplicação do Direito Administrativo e do Código de Proteção e Defesa do Consumidor.

Na tentativa de explicar tal situação o autor busca as origens do Código de Proteção e Defesa do Consumidor no direito norte-americano, onde todos os serviços, incluindo as public utilities Que mais se aproximam da noção brasileira de serviço público, submetem-se aos princípios da livre iniciativa, inexistindo a figura do serviço público de titularidade do Estado.

Ao importar tal prática e aplicá-la aos serviços públicos, no entanto, algumas das diferenças fundamentais entre as atividades econômicas e os serviços públicos devem ser destacadas.

A primeira delas diz respeito ao serviço público como função pública, no sentido de que o prestador de um serviço público, ao contrário do que ocorre nas atividades econômicas, deve almejar, em primeiro lugar, o interesse público. Daí porque the é dado promover alterações nas condiçóes de prestação do serviço, consoante decisões regulatórias tomadas no interesse da coletividade, às Quais o usuário deverá submeter-se, pois não poderá o prestador de serviço público assegurar o interesse isolado de um único usuário em detrimento do interesse da coletividade.

No que diz respeito ao usuário de serviço público, portanto, este não terá o seu interesse particular determinando a prestação do serviço, Que é estruturado para atender a coletividade.

Além disso, a disciplina Que regulamenta o serviço público é fixada por ato administrativo estatal, ao Qual o prestador do serviço se submete, não the sendo permitida a livre estipulação das condiçōes negociais como ocorre com as atividades econômicas.

Daí porque, no campo dos serviços públicos, os interesses tutelados não são disponíveis como no campo da atividade econômica privada, sendo admissível que o usuário, como parte economicamente mais fraca, tenha seus interesses sacrificados em prol do interesse da coletividade, o Que não ocorre no direito privado.

Por fim, há que se ter presente que os custos econômicos da tutela do usuário são arcados, ao fim e ao cabo, pela própria coletividade, ao contrário do Que ocorre no âmbito das atividades econômicas privadas, onde é o fornecedor Que, via de regra, arca com tal custo. Assim, as conseqüências de uma penalidade imposta ao prestador de serviço público atingirão a esfera de terceiros Que não possuem QualQuer relação com o usuário cujo interesse individual se está a proteger.

27 IUSTEN Fllmo, Marçal. Teoria Geral das Concessões de Serviço Público. São Paulo: Dialética, 2003, p. 552. 
Ao elencar todas essas diferenças, Marçal justen Filho conclui Que, havendo situações de incompatibilidade entre as regras do Código de Proteção e Defesa do Consumidor e as regras de direito administrativo, o princípio da proporcionalidade impõe a preponderância destas últimas. Segundo o autor, seria inviável aplicar ao serviço público as regras e princípios construídos para hípóteses de direito privado Quando incompatíveis com o princípio da supremacia e indisponibilidade do interesse público ${ }^{28}$.

Maria Cristina Cesar de Oliveira ${ }^{29}$ entende Que, sendo o serviço prestado diretamente pelo poder público, as normas do Código de Proteção e Defesa do Consumidor são meramente declaratórias, prestando-se apenas a reforçar as prescrições administrativas garantidoras da correta prestação dos serviços. A prestação direta dos serviços pela Administração Pública afastaria, por completo, a aplicabilidade de comandos do direito do consumidor que sejam incompatíveis com a natureza estatutária do serviço, como, por exemplo, o poder de alteração unilateral do contrato. A aplicação de certas normas consumeristas apenas seria possível, na hipótese de prestação direta do serviço pelo Estado, por força do próprio díreito administrativo.

lá no caso da prestação de serviços públicos por entes particulares, concessionários ou permissionários, entende a autora serem plenamente aplicáveis as normas do Código de Proteção e Defesa do Consumidor, Que se somariam às normas públicas fixadas pelo direito administrativo ${ }^{30}$.

Para Cláudia Lima Marques ${ }^{31}$, o regime dos contratos estabelecidos com a Administração Pública é especial, outorgando a ela faculdades que Quebram o equilíbrio do contrato com o usuário. Apesar de reconhecer a dificuldade de o direito do consumidor reequilibrar essa equação, a autora ressalta Que a tendência da Administração de impor alterações unilaterais prejudicando ainda mais a situação de vulnerabilidade do usuário tem sido amenizada pela jurisprudência. Em seu entender, a disciplina dos contratos de fornecimento de serviços públicos deverá conciliar as imposições do direito constitucional com a proteção do consumidor e as prerrogativas administrativas.

Sem embargo do reconhecimento, por parte destes ilustres estudiosos, da dificuldade de compatibilizar o direito do consumidor com o direito administrativo inerente ao regime dos serviços públicos, ponto comum entre eles é a aceitação da aplicação, ao menos na parte em Que tratou expressamente de disciplinar o assunto, do Código de Proteção e Defesa do Consumidor ao usuário de serviços públicos.

\footnotetext{
28 Ibid., p. 560.

29 OLIVEIRA, Maria Cristina Cesar de. O Código de Defesa do Consumidor e a Adninistração Pública. Interesse Público, Porto Alegre, Notadez, ano 5, n. 22, novembro/dezembro de 2003, p. 88-90.

so Ibid., p. 91.

31 MARQUES, Cláudia Lima. op. cit., p. 210 e 212.
} 


\section{TRATAMENTO CONSTITUCIONAL DO USUÁRIO DE SERVIÇO PÚBLICO}

\subsection{Análise da leqislação infraconstitucional à luz da Constituição Federal de 1988}

A legislação infraconstitucional, conforme exposto no capítulo anterior, tratou de equiparar o tratamento jurídico conferido ao usuário de serviço público a aquele estabelecido ao consumidor em geral, abarcando o primeiro conceito dentro da esfera do segundo.

Esta equivalência de conceitos é percebida em ambos os regimes jurídicos, uma vez Que tanto as normas de direito privado (mormente a Lei $n^{\circ} 8.078 / 90$ ) Quanto as normas de direito administrativo (em especial a Lei $n^{\circ} 8.978 / 95$ ) ocuparam-se de regular a proteção ao usuário de serviços públicos, sem afastar, por completo, a incidência umas das outras.

A doutrina e a jurisprudência pátria têm sido praticamente unânimes em determinar a aplicação, em maior ou menor grau, das normas consumeristas à proteção dos usuários de serviço público, admitindo, no mínimo, a coexistência dessas normas com as normas de direito administrativo para tais fins.

Por força do princípio da legalidade, no entanto, a legitimidade da alternância ou da simultaneidade da aplicação dos regimes jurídicos público e privado à regulamentação da defesa do usuário de serviço público apenas poderá ser verificada diante dos mandamentos superiores da Constituição Federal.

Tal análise, Que ora se passa a fazer, parte da sistemática verificada no próprio texto da Constituição Federal de 1988, dentro do qual é possível identificar, com clareza, a utilização dos vocábulos "consumidor" e "usuário" em passagens distintas.

Se é certo Que o Poder Constituinte utilizou-se com critério do vocabulário técnicojurídico presente no texto da Constituição, então a mera constatação do emprego das expressões "consumidor" de serviços e "usuário de serviços públicos" em dispositivos constitucionais distintos seria suficiente para concluir que elas se dirigem a realidades distintas.

Para melhor compreender a distinção apontada, faz-se necessário analisar, primeiramente, a diferença de tratamento conferida pela Constituição Federal às atividades econômicas e aos serviços públicos, para após pereuirir acerca da eventual distinção entre consumidor e usuário. 


\subsection{Diferença entre atividade econômica e serviço público}

A Constituiçăo Federal de 1988 reservou seu Título VIl ao tratamento da ordem econômica e financeira, disciplinando, no Capítulo I deste Título, os prỉncípios gerais da atividade econômica ${ }^{32}$.

Logo no art. 170, primeiro deste capítulo ${ }^{33}$, a Constituição Federal elenca os princípios da ordem econômica, fundada na valorizaçâo do trabalho humano e na livre iniciativa, dentre os euais se destaca a defesa do consumidor.

Em seu parágrafo único, o art. 170 introduz a expressão "atividade econômica", assegurando a todos seu livre exercício, independentemente de autorização, salvo Quando previsto em lei.

A exploraçâo dessa atividade econômica pelo Estado vem disposta no art. 173, Que a restringe às hipóteses de relevante interesse público ou de necessidade aos imperativos da segurança nacional. Nestes casos, a exploração de atividade econômica pelo Estado dar-se-á por meio de empresa pública ou sociedade de economia mista, Que não deverão gozar de privilégios fiscais não estendidos ao setor privado, nos termos dos parágrafos do referido artigo ${ }^{34}$.

32 Os demais Capilulos tratam da (i.) política urbana, (ii.) da política agrícola e fundiária e da reforma agrária e (iii.) do sisterna financeiro nacional.

${ }^{33}$ Dispốe o referido artigo: Art. 170. A ordem econômica, fundada na valorização do trabaho humano e na livre iniciativa, tem por lin assegurar a todos existência digna, conforme os ditames da justiça social, observados as seguintes princípios:

1 - soberania nacional;

Il - propriedade privada;

III - função social da propriedade;

IV - livre concorrência;

$V$ - defesa do consumidor;

$\mathrm{V}$ - defesa do meio ambiente, inclusive mediante tratamento diferenciado conforme o impacto ambiental dos produtos e serviços e de seus processos de elaboração e prestação; VI - reduçăo das desigualdades regionais e sociais;

VIII - busca do pleno emprego:

IX - tratamento favorecido para as empresas de pequeno porte constituidas sob as leis brasileiras e que tenham sua sede e administração no País.

Parágrafo único. É assegurado a todos o livre exercício de Qualquer atividade econômica, independentemente de autorização de órgăos públicos, salvo nos casos previstos em lei.

${ }^{34}$ Leia-se: Art. 173. Ressalvados os casos previstos nesta Constituiçăo, a exploraçäo direta de atividade econômica pelo Estado só será permitida Quando necessária aos imperativos da segurança nacional ou a relevante interesse coletivo, conforme definidos em lei.

$\S 1^{\circ}$ A lei estabeiecerá o estatuto jurídico da empresa pública, da sociedade de economia mista e de suas subsidiárias que explorem atividade econômica de produção ou comerciałização de bens ou de prestação de serviços, dispondo sobre:

1 - sua função social e formas de fiscalizaçăo pelo Estado e pela sociedade:

II - a suj̣eição ao regime jurídico próprio das empresas privadas, inclusive Quanto aos direitos e obrigações civis, comerciais, trabalhistas e tributários;

III - licitação e contratação de obras, serviços, compras e alienações, observados os princípios da administração pública;

IV - a constituição e o funcionamento dos consethos de administração e fiscal, com a participação de acionistas minoritários; 
A atuação do Estado nas atividades econômicas é. portanto, restrita: A ele cabe, primordialmente, desempenhar o papel de agente normativo e regulador, exercendo as funçóes de fiscalização, incentivo e planej̧amento, conforme disposto no art. 174 ${ }^{35}$.

A leitura conjunta destes três artigos permite identificar, portanto, algumas das características básicas das atividades econômicas, dentre elas o livre exercício pela iniciativa privada e a atuação apenas excepcional do Estado, cujo papel central é de regulação e fisçalização.

Diferentemente do Quanto previsto nos artigos anteriores, o art. 175 ocupa-se do tratamento conferido aos serviços públicos, cuja titularidade incumbe, tão-somente, ao poder público, ainda Que sua prestação se dê indiretamente, por meio dos institutos da concessão ou permissãa ${ }^{36}$. Não há, neste caso, livre iniciativa do setor privado, Que apenas prestará o serviço mediante delegação do Estado, sempre submetida a processo licitatório e sujeita à retomada a Qualquer tempo.

$V$ - os mandatos, a avaliação de desempenho e a responsabilidade dos administradores.

$\S 2^{\circ}$ - As empresas públicas e as sociedades de economia mista não poderão gozar de privilégios fiscais não extensivos às do setor privado.

$\S 3^{\circ}$ - A lei regulamentará as relaçöes da empresa pública com o Estado e a sociedade.

$\S 4^{\circ}$ - A lei reprimirá o abuso do poder econômico Que vise à dominação dos mercados, à eliminação da concorrência e ao aumento arbitrário dos lucros.

$\S 5^{\circ}$ - A lei, sem prejuízo da responsabilidade individual dos dirigentes da pessoa jurídica, estabelecerá a responsabilidade desta, sujeitando-a às puniçöes compativeis com sua natureza, nos atos praticados contra a ordern econômica e financeira e contra a economia popular.

35 Referido artigo dispõe da seguinte forma:

Art. 174. Como agente normativo e regulador da atividade econômica, o Estado excrcerá, na forma da lei, as funções de fiscalização, incentivo e planejamento, sendo este determinante para o setor público e indicativo para o setor privado.

$\S 1^{0}$ - A lei estabelecerá as diretrizes e bases do planejamento do desenvolvimento nacional equilibrado, o Qual incorporará e compatibilizará os planos nacionais e regionais de desenvolvimento.

$\S 2^{\circ}$ - A lei apoiará e estimulará o cooperativismo e outras formas de associativismo.

$\S 3^{\circ}$ - O Estado favorecerá a organização da atividade garimpeira em cooperativas, levando em conta a proteção do meio ambiente e a promoção econômico-social dos garimpeiros.

$\S 4^{\circ}$ - As cooperativas a Que se refere o parágrafo anterior teräo prioridade na autorização ou concessão para pesquisa e lavra dos recursos e jazidas de minerais garimpáveis, nas áreas onde estejam atuando, e naquelas fixadas de acordo com o art. 21, XXV, na forma da lei.

36 Assim dispóe o mencionado artigo:

Art. 175. Incumbe ao Poder Público, na forma da leị, diretamente ou sob regime de concessão ou permissão, sempre através de licitação, a prestação de serviços públicos.

Parágrafo único. A lei disporá sobre:

I - o regime das empresas concessionárias e permissionárias de serviços públicos, o caráter especial de seu contrato e de sua prorrogação, bem como as condições de caducidade, fiscalização e rescisão da concessão ou permissão;

l] - os direitos dos usuários;

III - política tarifária;

IV-a obrigaçäo de manter serviço adequado. 
O parágrafo único do art. 175 também contribui para delinear a diferença entre os princípios norteadores da atividade econômica e aQueles aplicáveis aos serviços públicos, elencando, dentre os últimos, os direitos dos usuários.

Tendo presente a distinção de tratamento acima mencionada, faz-se necessário, a fim de melhor compreender a inclusão dos serviços públicos no capítulo destinado à ordem econômica, efetuar uma diferenciação entre dois sentidos igualmente comuns da expressão "atividade econômica", um Que se refere a gênero e outro a espécie.

Eros Roberto $\mathrm{Grau}^{37}$ leciona que a atividade econômica enQuanto gênero inclui duas espécies: os serviços públicos, Que seriam as atividades econômicas prestadas preferencialmente pelo setor público (visto Que de titularidade do Estado), e as atividades econômicas em sentido de espécie, Que seriam preferencialmente prestadas pelo setor privado (e apenas excepcionalmente pelo poder público). Segundo o auțor, o serviço público está, assim, para o setor público da mesma forma como a atividade econômica está para o setor privado.

Inicialmente, verifica-se certa diffculdade de conceituação de serviço público e atividade econômica, cuj̣as definiçōes estão sujeitas a variações de acordo com o momento histórico, as opções políticas e a relação estabelecida entre as forças sociais representadas pelo capital e pelo trabalho. Em síntese, pretende o capital que todas as atividades passiveis de exploração lucrativa sejam reservadas à sua livre exploração, enQuanto, por outro lado, pretende o trabalho seja atribuído ao Estado o maior número de atividades, visando a uma exploração não especulativa ${ }^{38}$.

Não obstante a possibilidade de alargamento ou retração da noção de serviço público de acordo com a realidade histórica, é possível notar, na Constituição Federal de 1988 uma clara diferença entre atividade econômica em sentido estrito e serviço público, Que parte da diferença entre os regimes jurídicos aplicáveis a cada um deles.

As atividades econômicas estão reguladas no art. 173, enQuanto o regime aplicável aos serviços públicos está disposto no art. 175. O primeiro artigo esclarece, como adiantado acima, as hipóteses em que o Estado poderá prestar atividade econômica em sentido estrito, enQuanto o segundo esclarece as formas pelas Quais o Estado prestará os serviços públicos. direta ou indiretamente.

Para Almiro do Couto e Silva ${ }^{39}$, o regime do art. 173 é coerente com a livre iniciativa, elencada pelo art. 170 como princípio da ordem econômica. lá o art. 175 determina Que

\footnotetext{
GRAU, Eros Roberto. A Ordem Econômica ná Constituição de 1988. 5. ed. São Paulo: Malheiros, 2000, p. 133.

38 lbid., p. 140.

39 COUTO E SILVA, Almiro. Privatização no Brasil e o novo exercício de funções públicas por particulares. Serviços públicos "à brasileira"? Revista da Procuradoria Geral do Estado do Rio Grande do Sul, Porto Alegre, v.27, n. 57, p. 199-226, dez. 2003, p. 211.
} 
algumas das atividades econômicas de relevante interesse coletivo, a ponto de serem classificadas como serviço público, sejam exercidas diretamente pelo poder público, ou delegadas mediante concessão ou permissão.

No entendimento do autor ${ }^{40}$, o fato de o art. 175 estar inserido no capítulo destinado aos princípios gerais da atividade econômica leva à conclusão de Que os serviços públicos delegáveis por meio de concessão ou permissão são ąueles de natureza comercial e industrial.

Assim, não obstante se possa incluir a noção de serviço público dentro de um contexto mais amplo de atividade econômica, é certo que ele não se confunde com a atividade econômica em sentido estrito disciplinada no art. 173.

A atividade econômica em sentido estrito submete-se, nos termos da Constituição, a um regime de direito privado, pois embora regulada e fiscalizada pelo Estado, e até mesmo desenvolvida por ele em hipóteses excepcionais, deve ela observância aos princípios constitucionais da livre iniciativa, lacultando-se a todos o seu exercício, independentemente de autorização.

O serviço público, por outro lado, está submetido a um regime jurídico de direito público, uma vez Que não apenas sua regulação e fiscalização, mas sua própria titularidade pertence privativamente ao Estado, Que decidirá acerca da conveniência ou não de sua delegação a privados.

Essa distinção entre os regimes aplicáveis a cada um dos casos é bem explorada por Celso Antônio Bandeira de Mello, Que ao desempenhar atividades econômicas nos termos do art. 173, o Estado atua basicamente sob regime de direito privado, uma vez que a atividade econômica é própria dos particulares e, portanto, insuscetível de ser Qualificada como serviço público ${ }^{4 !}$.

O tratamento autônomo conferido pela Constituição Federal aos serviços públicos, amoldando-os ao regime jurídico próprio de sua execução também é ressaltado por Cármen Lúcia Antunes Rocha ${ }^{42}$, Que o difere daQuele utilizado para reger as relações privadas no âmbito da atividade econômica.

Em verdade, o regime jurídico-administrativo, ou seja, o regime de direito público ao Qual se submetem os serviços públicos thes é tão inerente que chega a ser tomado, por diversos autores, como elemento formal caracterizador da própria definição de serviço público ${ }^{43}$.

* Ibid., p. 210.

4 MELLO, Celso Antônio Bandeira de. Curso de Direito Administrativo. 15. ed. Săo Paulo: Malheíros, 2002 , p. 624.

42 ROCHA, Cármen Lúcia Antunes. Estudo sobre concessão e permissão de serviço público no direito brasileiro. São Paulo: Saraiva, 1996, p. 30.

43 Veja-se, neste sentido: DE MELLO, Celso Antônio Bandeira. op. cit.; p. 617; JUSTEN FILHO, Marçą̆. Curso de Direito Administrativo. Säo Paulo: Saraiva, 2005, p. 48I; FlGUEIREDO, Lúcia Valle. op. cit., p. 79. DI PIETRO, Maria Sylvia Zanella. op. cit., p. 98 e BLANCHET, Luiz Alberto. op. cit., p. 22. 
Evidente, portanto, Que a Constituição Federal tratou de distinguir, fundamentalmente em relação aos regimes jurídicos aplicáveis, as atividades econômicas dos serviços públicos.

\subsection{Conceito de consumidor versus conceito de usuário}

Da diferença existente entre atividade econômica (entendida, aqui, em seu sentido estrito) e serviço público deriva, também, a diferença entre os conceitos de consumidor e usuário.

O tratamento diverso disspensado pela Constituição ao consumidor e ao usuário do serviço público é capturado por Cintra do Amaral, Que ressalta, para tanto, o tratamento dos dois assuntos por dispositivos constitucionais diferentes ${ }^{44}$.

A primeira expressão, qual seja, "consumidor", é encontrada no bojo da disciplina das atividades econômicas, mais especificamente no art. $170 \mathrm{~V}$, da Constituição Federal, Que afirma ser a proteção do consumidor um dos princípios da ordern econômica, fundada na livre iniciativa. Trata-se, portanto, de princípio vinculado à atividade econômica, dado que, conforme já demonstrado, nâo há espaço para livre iniciativa no âmbito do serviço público.

Reforçando tal princípio, a Constituição Federal elenca a defesa do consumidor no rol dos direitos fundamentais, mais precisamente no art. $5^{\circ}, \mathrm{XXXIl}$, atribuindo ao Estado sua promoção, na forma da lei ${ }^{45}$.

Trata-se de uma das normas que consagram direitos individuais, as quais têm por funçāo básica a criação de uma área de liberdade em favor do indivíduo e infensa à intervenção do Estado. Essa, porém, não é a única função das normas de direito individual. No caso do art. $5^{\circ}$, XXXII. CF 1988, diferentemente da função básica de defesa do indivíduo contra o Estado, tem-se a obrigação do Estado de defender um direito individual contra limitações ou restrições vindas não dele. Estado, mas de terceiros. Trata-se, in casu. de "pretensão de defesa ou de proteção" ("Schutzanspruch"), a Qual "impõe ao Estado, nos casos extremos, o dever de agir contra terceiros" ${ }^{\prime 4}$. No caso ora em análise, a norma manda (implicitamente) que o Estado derrogue o direito obrigacional e contratual "comum" (o Direito do Código Civil), por meio de normas específicas de defesa ou proteção do consumidor contra terceiros, Quais sejam: os produtores e fornecedores de bens e serviços.

44 AMARAL, Antônio Carlos Cintra do. Distinção entre usuário de serviço público e consumidor. Revista Diálogo Jurídico, Salvador, CAl - Centro de Atualização lurídica, n. 13, abril/maio de 2002. Revista Eletrônica disponivel en <http:/www.direttopublico.com.br>. Acesso em: 17 de fevereiro de 2005, p. 04.

4s O teor do referido artigo está transcrito no primeiro capítulo, inserido na análise do surgimento do Código de Proteção e Defesa do Consumidor.

46 MENDES, Gilmar Ferreira. Os direitos fundamentais e seus múltiplos significados na ordem constilucional. Revista Diálogo lurídico, Salvador, CAI - Centro de Atuałizaçăo Jurídica, n. 10, laneiro de 2002. Revista Eletrônica disponivel na Internet: <hțtp:/ hww.direitopublico.com.br>. Acesso em: 07.03.2005, p. 3. 
Complementando o texto constitucional e visando a concretizar tal direito, o art. 48 do Ato das Disposições Constitucionais Transitórias determinou ao Congresso Nacional a elaboração de um código de direito do consumidor no prazo de cento e vinte dias após a promulgação da Constituiçãa ${ }^{47}$.

Atendendo a esta determinação e aos anseios não apenas do poder constituinte mas de toda a população, como já referido anteriormente, foi publicada, em I990, a Lei no 8.078 , o denominado Código de Proteção e Defesa do Consumidor.

A análise de sua base constitucional indica, assim, Que o Código de Proteção e Defesa do Consumidor origina-se da necessidade de regulamentar os direitos dos consumidores no âmbito das atividades econômicas, em especial nas relações entre consumidores e fornecedores privados Que atuam por sua livre iniciativa, mas também nas relações entre referidos consumidores e o Estado Quando este, em observâncias das hipóteses excepcionais previstas no art. 173, desempenha atividade econômica.

No que tange ao termo "usuário", cumpre observar, inicialmente, a ausência de sua menção em Quaisquer dos dispositivos constitucionais referentes à atividade econômica em sentido estrito. Tal observação é válida, da mesma forma, no sentido inverso, uma vez Que inexiste, nos dispositivos constitucionais atinentes ao serviço público, Qualeuer referência ao termo "consumidor".

Ao contrário, o vocábulo "usuário" surge, no bojo do Título VII da Constituição Federal, apenas no inciso Il do parágrafo único do art. 175, para determinar que a lei disporá sobre os direitos dos usuários de serviço público. Usuário, portanto, na literalidade e na sistemática do texto constitucional, é um conceito estritamente vinculado ao âmbito dos serviços públicos, Quer prestados diretamente pelo Estado, Quer delegados à iniciativa privada, por meio dos institutos da concessão ou da permissão, mediante licitação.

Corroborando esse entendimento, ao dispor sobre os princípios gerais da atuação da Administração Pública, a Constituição Federal indicou, no $\S 3^{\circ}$ do art. 37 , a forma de participação do usuário na administração pública, garantindo, em seus incisos l e ll, direitos dos usuários em face dos serviços públicos e registros administrativos. ${ }^{48}$

A vinculação dos conceitos de consumidor à atividade econômica e de usuário ao serviço público, efetuada de forma expressa no texto da Constituição Federal, não permite outra conclusão Que náo a de que se tratam de conceitos jurídicos absolutamente distintos entre si.

47 Conforme já exposto no capítulo anterior.

48 Art. 37: (...)

$\S 3^{\circ}$. A Lei disciplinará as formas de participação do do usuário na administração pública direta e inidireta, regulando especialmente:

1 - as reclamaçóes relativas à prestação dos serviços públicos em geral, asseguradas a manutenção de serviço de atendimento ao usuário e a avaliação periódica, externa e interna, da qualidade dos serviços;

Il - o acesso dos usuários a registros administrativos e a informações sobre atos de governo, observado o disposto no art. $5^{\circ}, \mathrm{X}$ e XXXIII; (...) 
E, na esteira da distinçâo, já destacada, entre os regimes aplicáveis aos serviços públicos e às atividades econômicas, inegável a submissão de cada um dos conceitos, de usuário e consumidor, aos respectivos regimes de direito público e de direito privado.

\subsection{Corolánio da distinção dos reqimes jurídicos: a Emenda Constitucional $\mathrm{N}^{\circ} 19 / 98$}

Como visto, o texto originário da Constituição Federal de 1988 estabelecia, por um lado, a vinculação do conceito de consumidor ao regime jurídico privado Que rege as atividades econômicas e, por outro, a llgação intrínseca da noção de usuário ao regime jurídico dos serviços públicos.

Tal distinção, decorrente da sistemática constitucional, esteve clara desde a promulgação da Constituição Federal de 1988 e, nāo obstante, as normas infraconstitucionais editadas promoverem a eQuiparação dos conceitos, aplicando ao usuário de serviço público o tratamento previsto para proteção do consumidor.

A questão que restava, diante do texto originário da Constituição Federal, era a seguinte: reconhecida a diferença entre os conceitos de usuário e consumidor, podería a legislação ordinária, para efetuar a proteção do usuário nos termos da lei, conforme exigido pelo inciso ll do parágrafo único do art. 173, remetê-ła ao Quanto previsto no Código de Proteção e Defesa do Consumidor publicado em observância do art. 48 do Ato das Disposições Constitucionais Transitórias?

Ou ainda: a "lei" exigida pelo inciso ll do parágrafo único do art. 173 podería ser uma lei editada para regulamentação de atividade econômica, como fora a Lei $n^{\circ} 8.078 / 90$ ? Ou será Que mesmo outra lei, editada especificamente para tratar dos serviços públicos, como no caso da Lei n $n^{\circ} 8.987 / 95$, poderia remeter a proteção dos usuários à norma anteriormente publicada para atender aos consumidores da atividade econômica?

Ainda Que o enfrentamento direto de tais Questões não tenha se verificado na doutrina, é certo Que se procurou legitimar a aplicação do Código de Proteção e Defesa do Consumidor aos usuários de serviço público alegando-se que o atendimento à exigência constitucional de proteção por meio de let fora devidamente cumprido pelas Leis $\mathrm{n}^{\circ} 8.078$ / 90 e $8.987 / 95^{49}$.

Ainda que esta coincidência de regimes pudesse ser sustentável Quando da publicação do Código de Proteção e Defesa do Consumidor, em 1990, ou mesmo quando da publicação da Lei Geral de Concessóes e Permissões de Serviço Público, em 1995, em face do texto original da Constituição Federal de I 988, tal entendimento apenas perduraria incólume por um espaço limitado de tempo.

49 Conforme amplamente demonstrado no primeiro capítulo, tal tarefa foi cumprida pela Quase que unanimidade da doutrina, quer especializada em direito do consumidor, quer em direito administrativo. 
A partir de 1998, com o advento da Emenda Constitucional n ${ }^{\circ} 19$, a admissão do Código de Proteção e Defesa do Consumidor eneuanto lei de proteção dos usuários de serviços públicos para os fins do inciso II do parágrafo único do art. 173 da Constituição Federal tornou-se tarefa, senão inviável, consideravelmente mais árdua.

É Que, por meio da Emenda Constitucional no 19, de 04 de junho de 1998, introduziuse a necessidade de promulgação de lei específica para regulamentar a defesa do usuário de serviços públicos. Veja-se, para bem esclarecer a Questão, o teor do art. 27 da Emenda Constitucional no [9:

"Art. 27. O Congresso Nacional, dentro de cento e vinte dias da promulgação desta Emenda, elaborará lei de defesa do usuário de serviços públicos."

Com este dispositivo, o Poder Constituinte Derivado fez consłar, expressamente em norma constitucional, seu entendimento de Que o usuário de serviço público deve ter sua proteção efetuada por lei específica, inadmitindo, portanto, a aplicação direta do Código de Proteção e Defesa do Consumidor para tal finalidade.

Coroou-se, assim, não apenas a diferença entre os conceitos de usuário e de consumidor, mas também a distinção dos regimes jurídicos aplicáveis à proteçẫo de cada uma das figuras encontradas no âmbito dos serviços públicos ou no das atividades econômicas, Que fá se mostravam distintos na sistemática original da Constituição Federal de 1988.

Trata-se, no entendimento de Cintra do Amaral ${ }^{50}$, do reconhecimento implícito de Que a defesa do usuário de serviço público é juridicamente diversa da defesa do consumidor regulada pela Lei no 8.078/90.

A partir da promulgação da Emenda Constitucional no 19 , portanto, a utílização do Código de Proteção e Defesa do Consumidor como sucedâneo da lei de defesa do usuário de serviço público prevista no inciso II do parágrafo único do art. I 73 da Constituição Federal nāo mais pode ser livremente admitida.

Encontra-se, hoje, constitucionalmente evidenciada a diferença entre a proteção do consumidor e a proteçâo do usuário, bem como a necessidade de lei específica para dispor sobre esta última.

Não obstante, permanece grande parte da doutrina admitindo, sem restrições, a aplicação do Código de Proteção e Defesa do Consumidor para a promoção da defesa dos usuários de serviços públicos, omitindo -se da análise da exigência constitucional de legislação específica, introduzida pela mencionada Emenda Constitucional.

s) Ibid., p. 04. 
Rara exceção a essa regra é Juarez Freitas ${ }^{5 !}$, Que ao enfatizar a urgência da edição da nova regra demanda pela Emenda Constitucional $n^{\circ} 19 / 98$, a justifica para fins de ampliar e fortalecer a proteção do usuário de serviço público, sem afastar, no entanto, a incidência do Código de Proteção e Defesa do Consumidor para tanto.

O fato de a lei específica para proteção do usuário de serviços públicos, passados cerca de sete anos do prazo determinado pela Emenda Constitucional $n^{\circ} \mid 9$, ainda não tenha sido publicada, não admite sua mera substituição pela lei previamente existente para disciplinar a defesa dos consumidores. Esta também, vale lembrar, não observou o prazo determinado no Ato das Disposições Constitucionais Transitórias para sua publicação, o Que não lhe tira, certamente, a validade e importância.

É apenas e tão-somente por meio desta nova lei, uma espécie de "Código de Proteção e Defesa do Usuário de Serviços Públicos" que se poderia cogitar da regulamentação da proteção do usuário para os fins do inciso II do parágrafo único do art. 173 da Constituição Federal e, Quiçá, da própria admissão da aplicação subsidiária do Código de Proteção e Defesa do Consumidor para tal fim.

A constitucionalidade dessa possibilidade de aplicação subsidiária das normas da Lei $n^{\circ} 8.078 / 90$ para disciplinar a defesa do usuário de serviços públicos dependerá, frise-se, de determinaçäo expressa da nova lei, elaborada em atendimento da exigência do art. 27 da Emenda Constitucional $n^{\circ} 19^{52}$.

Para Cintra do Amaral, tal aplicação subsidiária do Código de Proteção e Defesa do Consumidor ao usuário de serviço público, ainda Que determinada pela nova lei, seria equivocada, uma vez que serviria para perpetuar a confusão atualmente existente entre as duas relações jurídicas, a de serviço público e a de consumo ${ }^{53}$.

Já Marçal Justen Filho admite, desde já, a aplicação subsidiária do direito do consumidor no âmbito dos serviços públicos, porém de forma não integral, a fim de Que vantagens especiais de um único usuário não inviabilizem a oferta do serviço público em favor dos demais. A regra do art. 27 da Emenda Constitucional no 19/98 é, para o autor, o reconhecimento de Que tais regras não podem ser aplicadas de forma automática e indiferenciada aos sèrviços públicos ${ }^{54}$.

51 FREJTAS, Juarez. O Controle Social e o Consumidor de Serviços Públicos. Revista Diálogo lurídico, Salvador, CA - Centro de Atualizaçăo lurídica, v. 1, nº 1, 200 l. Revista Eletrônica disponível em <http:/ /www.direitopublico.com.br>. Acesso em: 25 de março de 2005, p. 10.

52 Rodrigo Alves da Silva aponta, em seli estudo, a existência de anteprojeto de lei elaborado por comissão de juristas formada pelo extinto Ministério da Reforma Administrativa - MARE visando à disciplinar os direitos dos usuários que previa, precisamente, a aplicação subsidiária do Código de Proteção e Defesa do Consumidor. Cf. SILVA, Rodrigo Alves da. O Código de Defesa do Consumidor e os serviços públicos: a defesa dos usuários de serviço público. Jus Navigandi, Teresina, a. 7, n. 63, mar, 2003. Disponível em: <https:/ /wwwl.jus.com.br/doutrina/texto.asp?id $=3830>$. Acesso em: 14 de março de 2005.

s3 AMARAL, Antônio Carlos Cintra do. op. cit., p. 04.

54 IUSTEN FIl.HO, Marçal. Curso de Direito Administrativo. Săo Paulo: Saraiva, 2005, p. 493. 
Certo é, no entanto, Que tal aplicação subsidiária das normas consumeristas privadas apenas poderia ser admitida caso determinada pela lei destinada especificamente à regulação da proteção do usuário de serviço público, sendo descabida a determinação do próprio Código de Proteção e Defesa do Consumidor de auto-aplicação ao serviço público.

Tratando-se, porém, de hipótese de lege ferenda, resta tentar esclarecer a razão pela cual a quase que unanimidade da doutrina e da jurisprudência permanecem aplicando o Código de Proteção e Defesa do consumidor aos usuários de serviço público sem Qualquer Questionamento acerca de sua constitucionalidade.

\section{TRATAMENTO DO USUÁRIO DE SERVIÇO PÚBLICO NA PRÁTICA}

\subsection{Compatibilidade prática entre as normas infraconstitucionais e a obriqação constitucional de lei específica}

Conforme demonstrado no capítulo anterior, a literalidade e a sistemática da Constituição Federal, mormente após a promulgação da Emenda Constitucional n $n^{\circ} 19$, de 04 de junho de 1998, impedem a aplicação direta do Código de Proteção e Defesa do Consumidor ao usuário de serviços públicos.

Viu-se, porém, no primeiro capítulo, Que não apenas a legislação infraconstitucional pretendeu a aplicação das normas consumeristas ao usuário de serviço público, como tal pretensão tem sido constantemente corroborada e aplaudida pela doutrina nacional e pela jurisprudência de nossos tribunais.

Resta, assim, Questionar, diante da aparente incompatibilidade entre os preceitos da Constituição Federal e o entendimento geral da doutrina acerca da legisilação infraconstitucional, em Que medida este último comportamento pode ser explicado à luz da realidade fática e jurídica de nosso país.

Não parece razoável sustentar Que a doutrina e a jurisprudência pátria ignorem os preceitos constitucionais. Ao contrário, disso sequer se cogita no presente estudo. $O$ que se busca, conforme esclarecido acima, são as razões que levam nossos estudiosos a defenderem a aplicação de um entendimento aparentemente inconstitucional.

A explicação de tal conduta deve partir, obrigatoriamente, do campo da realidade prática, Que impóe a necessidade de se garantir, aos usuários de serviços públicos, a indispensável proteção diante dos prestadores de tais serviços, Quer seja o Estado diretamente, Quer sejam particulares concessionários ou permissionários.

O Quê, por óbvio, não se pode negar, mormente diante do texto constitucional, éo direito do usuário de serviço público de receber proteção por meio de um regime jurídico efetivo. 
A clareza desta necessidade, já percebida pelo Poder Constituinte Originário, ao elencar os direitos do usuário de serviço público no inciso II do parágrafo único do art. 175 da Constituição Federal, veio a ser apenas reforçada pelo Poder Constituinte Derivado, ao determinar a elaboração de lei destinada à sua proteção no art. 27 da Emenda Constitucional n०19, de 1998.

Ora, se o texto constitucional sempre primou pela defesa dos usuários de serviços públicos, não seria razoável imaginar Que durante os cerca de 10 anos Que se passaram entre a promulgação da Constituição e da referida Emenda Constitucional se pudesse negar, ao abrigo da própria Constituição, efetividade à proteção dos referidos usuários.

Em outras palavras, não se poderia impedir a defesa eficaz dos direitos dos usuários sob o argumento de Que as normas constitucionais, por serem programáticas ou de eficácia contida, seriam inaplicáveis na prática.

Ao contrário, a implementação eficiente da defesa do usuário é medida Que atende ao escopo da Constituição Federal, ainda Que efetuada mediante aplicação de normas destinadas à defesa dos consumidores no âmbito das atividades econômicas sujeitas à livre iniciativa.

\subsection{Da aplicação por analogia das normas de direito privado e seus cuidados especiais}

Admite-se, portanto, Que o Código de Proteção e Defesa do Consumidor possa ser aplicado para resguardar os direitos dos usuários de serviço público mediante analogia, em face da já mencionada semelhança entre a posição ocupada por usuários e consumidores nas relações estabelecidas entre eles e seus respectivos fornecedores.

A aplicação analógica das regras materiais de proteção do consumidor ao usuário de serviço público pode ser considerada, nesse contexto, medida Que satisfaz o interesse público envolvido na prestação de serviço público e, precipuamente, a intenção do próprio poder constituinte, Quer originário, Quer derivado.

Como toda a aplicação fundada na analogia, no entanto, os cuidados a serem dispensados ao se aplicar o Código de Proteção e Defesa do Consumidor à relação estabelecida entre usuário e prestador de serviço público devem ser redobrados.

De fato, as peculiaridades Que caracterizam tal relação como de direito administrativo exigem cautela na proteção do consumidor, uma vez Que. conforme já demonstrado, a regulamentação dos serviços públicos visa ao atendimento não apenas do usuário isoladamente considerado, mas da coletividade de usuários representada pelo interesse público.

Essas peculiaridades já foram apontadas por Marçal Justen Filho, Que embora admita a aplicação direta (e não analógica) do direito do consumidor ao usuário de serviço público, o 
faz com ressalvas, apontando para a inviabilidade de aplicar ao serviço público as normas editadas para regulamentar serviços privados Quando incompatíveis com os princípios da supremacia e indisponibilidade do interesse público ${ }^{55}$.

Assim, por exemplo, ao se determinar a continuidade dos serviços públicos essenciais com base no Código de Proteção e Defesa do Consumidor, é preciso que se tenha presente Que tal continuidade deve ser garantida à totalidade dos usuários. Isso significa Que a inadimplência de um único usuário Que continua a desfrutar do serviço público a bem de uma "continuidade privatista" provocará prejuízos a todos os demais, Quer pela redistribuição direta do ônus entre os adimplentes, Quer pela deterioração da Qualidade geral do serviço público prestado sem a contraprestação necessária.

Da mesma forma, não se poderia cogitar da indenização a um único usuário em razão de alteraçóes efetuadas unilateralmente na forma da prestação do serviço pela Administração Pública, uma vez que tal prerrogativa, a par de inerente ao serviço público, é realizada sempre com vistas à melhor perseguição do interesse público.

Daí poreue a aplicação analógica do Código de Proteção e Defesa do Consumidor não pode ser estendida para além das normas estritamente compatíveis com o regime público da sua prestação. Havendo conflito entre o direito do consumidor e as normas de direito administrativo, a prevalência destas últimas é inerente, porque especificamente elaboradas para regulamentar os serviços públicos.

Com isso entende-se Que, não obstante os artigos da Lei n $n^{\circ} .078 / 90$ Que tratam expressamente da disciplina dos serviços públicos sejam contrários ao texto literal da Constituição Federal, há Que se admitir a aplicação das regras do Código de Proteção e Defesa do Consumidor aos usuários de serviços públicos por analogia, apenas naquilo em Que não conflitam com as normas de direito administrativo e, evidentemente, até que a lei de proteção dos usuários de serviço público reclamada pelo art. 27 da Emenda Constitucional no 19/98 seja editada.

\section{CONCLUSÃo}

Tratou-se, ao longo do presente estudo, de investigar o regime jurídico aplicável à proteção dos direitos dos usuários nas relações estabelecidas com os prestadores de serviços públicos, Quer Quando prestados diretamente pela Administração Pública, Quer Quando delegados a particulares mediante concessão ou permissão.

${ }^{55}$ Id. Concessões de Serviço Público. I. ed. São Paulo: Dialética, 1997, p. 133. 
Não resta dúvida de Que essa proteção é almejada pela Constituição Federal e nela encontra-se expressamente prevista, não apenas no texto originário, Que já tratava dos direitos dos usuários de serviços públicos, inclusive diferenciando os dos consumidores no âmbito das atividades privadas, mas ainda na Emenda Constitucional no $19 / 98$, Que determinou a elaboração de norma específica para disciplinar os direitos dos usuários de serviços públicos.

Não obstante referida lei de proteção do usuário de serviço público não tenha sido, até o presente momento, editada, resta evidenciada a preocupação da legislação infraconstitucional, da doutrina e da jurisprudência pátria em promover, na prática, a defesa desses interesses.

Constatou-se, neste sentido, Que a legislação infraconstitucional tratou de promover a defesa do usuário de serviço público por meio de normas de direito privado, em especial o Código de Proteção e Defesa do Consumidor, Que contém artigos destinados, expressamente, à regulação dos serviços públicos.

Causa espécie que a quase totalidade da doutrina e da jurisprudência nacionais defenda a aplicação das referidas normas sem levantar Quaisquer Questionamentos acerca de sua constitucionalidade, mormente diante da flagrante diferença de tratamento conferida pela Constituição Federal ao consumidor de atividade econômica sujeita à livre iniciativa e ao usuário de serviço público.

O escasso tratamento da Questão pela doutrina e pelo Tribunais parece coadunar-se com a inerente necessidade de difusão de uma eficaz proteção do usuário de serviço público. Que, por óbvio, atende aos anseios da sociedade e ao próprio interesse público almejado pela Constituição Federal.

Tal medida, no entanto, não afasta a aparente inconstitucionalidade das normas privadas Que tratam de serviços públicos, tampouco a premente necessidade de se editar a lei específica exigida pelo Poder Constituinte Derivado.

Até que tal medida seja implementada, no entanto, há que se admitir a aplicação das normas do Código de Proteção e Defesa do Consumidor ao usuário de serviços público por analogia, a fim de evitar que seus legítimos interesses restem desprotegidos.

Tal aplicação analógica deverá sempre levar em consideração as especificidades do regime dos serviços públicos, afastando-se sua utilização Quando em confronto com as normas de direito administrativo ou Quando prejudiciais ao interesse público envolvido na prestação de tais serviços. 


\section{REFERÊNCIAS BIBLIOGRÁFICAS}

AMARAL, Antônio Carlos Cintra do. Distinção entre usuário de serviço público e consumidor. Revista Diálogo Jurídico, Salvador, CAJ - Centro de Atualização lurídica, n. 13, abril/maio de 2002. Revista Eletrônica disponível em <http://www.direitopublico.com.br>. Acesso em: 17 de fevereiro de 2005 .

BLANCHET, Luíz Alberto. Concessão de Serviços Públicos. 2. ed. Curitiba: Juruá, 1999.

CAPELETTO, Gilberto José. Direito dos Consumidores e Regulação dos Serviços Públicos. Marco Regulatório, Porto Alegre, AGERGS, n. 4, p. 31-63, 2001.

COUTO E SILVA, Almiro. Privatização no Brasil e o novo exercício de funções públicas por particulares. Serviços públicos "à brasíleira"? Revista da Procuradoria Geral do Estado do Rio Grande do Sul, Porto Alegre, v.27, n. 57, p. 199-226, dez. 2003.

DI PIETRO, Maria Sylvia Zanella. Direito Administrativo. 13. ed. São Paulo: Atlas, 2001 .

FIGUEIREDO, Lúcia Valle. Curso de Direito Administrativo. 6. ed. São Paulo: Malheiros, 2003.

FREITAS, Juarez. O Controle Social e o Consumidor de Serviços Públicos. Revista Diálogo Jurídico, Salvador, CAl - Centro de Atualização lurídica, v. 1, n. 1, 2001. Revista Eletrônica disponível em <http://www. direitopublico.com.br>. Acesso em: 25 de março de 2005.

GASPARINI, Diógenes. Direito Administrativo. 4. ed. São Paulo: Saraiva, 1995.

GRAU, Eros Roberto. A Ordem Econômica na Constituição de 1988. 5. ed. São Paulo: Malheiros, 2000.

GRINOVER, Ada Pellegrini. et al. Código brasileiro de defesa do consumidor: comentado pelos autores do anteprojeto. 5. ed. Rjo de Janeiro: Forense Universitária, 1998.

GROTTI, Dinorá Adelaide Musetti. O Serviço Público e a Constituição Brasileira de 1988. São Paulo: Malheiros, 2003.

IUSTEN FlLHO, Marçal. Curso de Direito Administrativo. São Paulo: Saraiva, 2005.

IUSTEN FILHO, Marçal. Teoria Geral das Concessôes de Serviço Público. São Paulo: Dialética, 2003.

MARQUES, Cláudia Lima. Contratos no Código de Defesa do Consumidor: o novo regime das relações contratuais. 3. ed. São Paulo: Editora Revista dos Tribunats, 1998.

MELLO, Celso Antônio Bandeira de. Curso de Direito Administrativo. 15. ed. São Paulo: Malheiros, 2002.

MEIRELLES, Hely Lopes. Direito Administrativo Brasileiro. 25. ed. São Paulo: Malheiros, 2000.

MEIRELLES, Hely Lopes. Licitação e Contrato Administrativo. 12. ed. São Paulo: Malheiros, 1999. 
MENDES, Gilmar Ferreira. Os direitos fundamentais e seus múltiplos significados na ordem constitucional. Revista Diálogo Jurídico, Salvador, CAI - Centro de Atualização lurídica, n. 10. laneiro de 2002. Revista Eletrônica disponivel na Internet: <http://www.direitopublico.com.br>. Acesso em: 07.03.2005, p. 3.

MIRAGEM, Bruno. A regulaçäo do serviço público de energia elétrica e o direito do consumidor. Revista de Direito do Consumidor, São Paulo, Revista dos Tribunais, n. 51, p. 68-100, julho-setembro 2004.

MOOR, Fernanda Stracke. O Regime de Delegação da Prestação de Serviços Públicos, 1. ed. Porto Alegre: Livraria do Advogado, 2002.

NASCIMENTO, Tupinambá Miguel Castro do. Comentários ao código do consumidor. Rio de Janeiro: Aide, 1991.

OLIVEIRA, Maria Cristina Cesar de. O Código de Defesa do Consumidor e a Administração Pública. Interesse Público, Porto Alegre, Notadez, ano 5, n. 22, novembro/dezembro de 2003.

OLIVEIRA, Ruth Helena Pimentel de. Entidades Prestadoras de Serviços Públicos e Responsabilidade Extracontratual. São Paulo: Atlas. 2003.

PFEIFFER, Roberto Augusto Castellanos. Serviços públicos concedidos e proteção do consumidor. Conferências do $5^{\circ}$ Congresso Brasileiro de Direito do Consumidor. Revista de Direito do Consumidor, São Paulo, Revista dos Tribunais, n. 36, p. 164-176, outubro-dezembro 2000.

ROCHA, Cármen Lúcia Antunes. Estudo sobre concessão e permissão de serviço público no direito brasileiro. São Paulo: Saraiva, 1996.

SAAD, Gabriel Eduardo. Comentários ao Código de Defesa do Consumidor: lei n. 8.078. de 11.9.90. 4. ed. São Paulo: LTr, 1999.

SILVA, Rodrigo Alves da. O Código de Defesa do Consumidor e os serviços públicos: a defesa dos usuários de serviço público. lus Navigandi, Teresina, a. 7, n. 63, mar. 2003. Disponível em: <https://wwwl .jus.com.br/doutrina/texto .asp?id=3830>. Acesso em: 14 de março de 2005 . 